\title{
Familial Aggregation of Lymphoplasmacytic Lymphoma/Waldenström Macroglobulinemia with Solid Tumors and Myeloid Malignancies
}

\author{
Sigurdur Y. Kristinsson ${ }^{a}$ Lynn R. Goldin ${ }^{c}$ Ingemar Turesson ${ }^{b}$ \\ Magnus Björkholm ${ }^{a}$ Ola Landgren ${ }^{a, d}$ \\ aDivision of Hematology, Department of Medicine, Karolinska University Hospital, Solna and Karolinska Institutet,

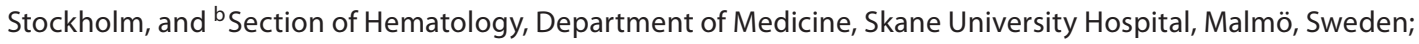 \\ 'National Cancer Institute, and d Medical Oncology Branch, Center for Cancer Research, National Cancer Institute, \\ National Institutes of Health, Bethesda, Md., USA
}

\section{Key Words}

Autoimmunity $\cdot$ Familial aggregation $\cdot$ Hematological

malignancies $\cdot$ Lymphoplasmacytic lymphoma/

Waldenström macroglobulinemia $\cdot$ Monoclonal

gammopathy of undetermined significance $\cdot$ Solid tumors

Susceptibility

\begin{abstract}
Lymphoplasmacytic lymphoma (LPL)/Waldenström macroglobulinemia (WM) is a B-cell disorder resulting from the accumulation, predominantly in the bone marrow, of clonally related lymphoplasmacytic cells. LPL/WM is a very rare disease, with an incidence rate of 3-4 cases per million people per year. Currently, the causes of LPL/WM are poorly understood; however, there are emerging data to support a role for immune-related factors in the pathogenesis of LPL/WM. In addition, data show that genetic factors are of importance in the etiology of LPL/WM. In this paper, we will review the current knowledge about familiality of LPL/WM and provide novel data on solid tumors and myeloid malignancies in firstdegree relatives of LPL/WM patients.
\end{abstract}

Copyright $\odot 2012$ S. Karger AG, Basel

\section{Introduction}

Lymphoplasmacytic lymphoma (LPL)/Waldenström macroglobulinemia (WM) is a $\mathrm{B}$-cell disorder resulting from the accumulation, predominantly in the bone marrow, of clonally related lymphoplasmacytic cells $[1,2]$. WM is a subset of LPL and can be distinguished clinically on the basis of a monoclonal immunoglobulin $\mathrm{M}$ (IgM) protein in serum [1]. LPL/WM is a very rare disease, with an incidence rate of 3-4 cases per million people per year [3].

Currently, the causes of LPL/WM are poorly understood. The strongest risk factor for WM is the precursor condition monoclonal gammopathy of undetermined significance (MGUS) of the IgM class, which is associated with an average $1.5 \%$ annual risk of developing nonHodgkin lymphomas [4]. There are emerging data to support a role for immune-related factors in the pathogenesis of LPL/WM [5]. In addition, data show that genetic factors are of importance in the etiology of LPL/WM.

\section{KARGER}

Fax +4161306 1234 E-Mail karger@karger.ch www.karger.com
(C) 2012 S. Karger AG, Basel

0001-5792/12/1273-0173\$38.00/0

Accessible online at:

www.karger.com/aha
Sigurdur Yngvi Kristinsson, MD, PhD

Division of Hematology, Department of Medicine

Karolinska University Hospital Solna

SE-171 76 Stockholm (Sweden)

Tel. +46 85177 0000, E-Mail sigurdur.kristinsson@ karolinska.se 
Table 1. Relative risk of lymphoproliferative disorders among first-degree relatives of LPL/WM patients [9]

\begin{tabular}{lllc}
\hline & $\begin{array}{l}\text { Relatives of } \\
\text { LPL/WM patients } \\
(\mathrm{n}=6,177)\end{array}$ & $\begin{array}{l}\text { Relatives of } \\
\text { LPL/WM controls } \\
(\mathrm{n}=24,609)\end{array}$ & $\begin{array}{l}\text { Relative risk } \\
(95 \% \text { CI })\end{array}$ \\
\hline LPL/WM & 10 & 2 & $20.0(4.1-98.4)$ \\
Non-Hodgkin lymphoma & 43 & 58 & $3.0(2.0-4.4)$ \\
Chronic lymphocytic leukemia & 16 & 19 & $3.4(1.7-6.6)$ \\
Hodgkin lymphoma & 4 & 21 & $0.8(0.3-2.2)$ \\
Multiple myeloma & 11 & 27 & $1.6(0.8-3.2)$ \\
MGUS & 5 & 4 & $5.0(1.3-18.9)$ \\
\hline
\end{tabular}

\section{Familiality and LPL/WM}

Familial clustering in LPL and WM has been observed in several studies [6-8]. In one study, including $257 \mathrm{WM}$ patients, $19 \%$ of the patients had at least one first-degree relative affected with WM or another B-cell disorder, including non-Hodgkin lymphoma, multiple myeloma, chronic lymphocytic leukemia, MGUS, acute lymphoblastic leukemia, and Hodgkin lymphoma [8]. The authors also found patients with a familial history of WM or a plasma cell disorder to have greater bone marrow involvement. In a large study from Sweden, including 2,144 LPL/WM patients, 8,279 population-based matched controls and linkable first-degree relatives of patients $(\mathrm{n}=$ $6,177)$ and controls $(n=24,609)$, we found first-degree relatives of LPL/WM patients to have a significantly increased risk of developing LPL/WM, other subtypes of non-Hodgkin lymphoma and MGUS, but not Hodgkin lymphoma or multiple myeloma, compared to first-degree relatives of controls (table 1) [9]. The excess risks were similar among parents, siblings and offspring, which favor the operation of dominant or codominant gene effects, rather than recessive genes. Together with previous studies [10-12], our findings support a role for shared common susceptibility genes that predispose to LPL/ WM and certain other lymphoproliferative disorders. Given the implications for future studies aimed at uncovering underlying susceptibility genes, it is important to define the spectrum of tumors associated with LPL/WM. Therefore, we analyzed risks of myeloid hematological malignancies and solid tumors among first-degree relatives of LPL/WM patients, using the database described above. As shown in table 2, first-degree relatives of LPL/ WM patients did not have an increased risk of myeloid malignancies [relative risk $(\mathrm{RR})=1.0 ; 95 \%$ confidence interval (CI) 0.6-1.7], including acute myeloid leukemia, myelodysplastic syndromes, chronic myeloproliferative neoplasms and chronic myeloid leukemia. In addition, first-degree relatives of LPL/WM patients had no increased risk of 'any solid tumor' (RR $=1.08$; 95\% CI $0.98-$ 1.19). Among the 28 solid tumors tested, relatives of LPL/ WM patients had only a borderline significantly increased risk of pancreas cancer $(\mathrm{RR}=1.8$; $95 \%$ CI $1.03-$ $3.1 ; \mathrm{p}=0.047)$. No significantly increased risk was found for any other solid tumor. Our finding of a significant increase in the risk of pancreas cancer has not been previously described and is of unclear significance. Due to the number of malignancies tested, we believe that these results can probably be explained by multiple testing and need to be confirmed in other series. Also, due to the inherent limitations of the Multigenerational Registry, we only have information on approximately $75 \%$ of first-degree relatives. However, as the approach and completeness is the same in patients and controls, the risk of bias is minimal. Furthermore, Altieri et al. [13] found that a parental history of cancer of the stomach increased the familial risk of LPL; however, we did not observe an increased risk of stomach cancer in our study. Our findings suggest that there are differences in genetic susceptibility to LPL/WM and to myeloid malignancies or solid tumors.

\section{Familiality, Autoimmune Diseases and LPL/WM}

A previous personal history of autoimmune disease has been shown to increase the risk of LPL/WM [14]. Recently, this has also been investigated in family members of LPL and WM patients. In a study including $103 \mathrm{WM}$ patients and 272 unaffected relatives from 35 multiple- 
Table 2. Relative risk of solid tumors and myeloid malignancies among first-degree relatives of LPL/WM patients

\begin{tabular}{|c|c|c|c|c|}
\hline Tumor site & $\begin{array}{l}\text { Relatives of } \\
\text { LPL/WM patients } \\
(\mathrm{n}=6,177)\end{array}$ & $\begin{array}{l}\text { Relatives of } \\
\text { LPL/WM controls } \\
(\mathrm{n}=24,609)\end{array}$ & $\begin{array}{l}\text { Relative risk } \\
(95 \% \mathrm{CI})^{1}\end{array}$ & $\begin{array}{l}\mathrm{p} \\
\text { value }\end{array}$ \\
\hline Myeloid malignancies & 18 & 71 & $1.0(0.6-1.7)$ & 1.00 \\
\hline Acute myeloid leukemia/myelodysplastic syndromes & 9 & 21 & $1.7(0.8-3.7)$ & 0.17 \\
\hline Chronic myeloproliferative neoplasm & 6 & 38 & $0.6(0.3-1.5)$ & 0.35 \\
\hline Chronic myeloid leukemia & 3 & 12 & $1.0(0.3-3.5)$ & 1.00 \\
\hline Any solid tumor & 581 & 2,150 & $1.08(0.98-1.19)$ & 0.06 \\
\hline Buccal & 6 & 34 & $0.7(0.3-1.7)$ & 0.55 \\
\hline Salivary gland & 0 & 9 & 0 & 0.21 \\
\hline Esophageal & 3 & 14 & $0.9(0.2-3.0)$ & 1.00 \\
\hline Stomach & 18 & 49 & $1.5(0.9-2.5)$ & 0.17 \\
\hline Small intestines & 4 & 6 & $2.7(0.7-9.4)$ & 0.12 \\
\hline Colon & 31 & 129 & $1.0(0.6-1.4)$ & 0.92 \\
\hline Rectal & 24 & 69 & $1.4(0.9-2.2)$ & 0.19 \\
\hline Liver & 4 & 24 & $0.7(0.2-1.9)$ & 0.63 \\
\hline Gallbladder & 3 & 10 & $1.2(0.3-4.3)$ & 0.73 \\
\hline Pancreas & 18 & 40 & $1.8(1.03-3.1)$ & 0.047 \\
\hline Larynx & 4 & 5 & $3.2(0.9-11.9)$ & 0.09 \\
\hline Lung & 27 & 109 & $1.0(0.6-1.5)$ & 1.00 \\
\hline Renal & 12 & 48 & $1.0(0.5-1.9)$ & 1.00 \\
\hline Bladder & 13 & 72 & $0.7(0.4-1.3)$ & 0.34 \\
\hline Melanoma skin & 41 & 126 & $1.3(0.9-1.8)$ & 0.15 \\
\hline Non-melanoma skin & 36 & 130 & $1.1(0.8-1.6)$ & 0.62 \\
\hline Brain & 20 & 59 & $1.4(0.8-2.2)$ & 0.26 \\
\hline Spinal cord & 0 & 8 & 0 & 0.37 \\
\hline Thyroid & 9 & 36 & $1.0(0.5-2.1)$ & 1.00 \\
\hline Bone & 3 & 12 & $1.0(0.3-3.5)$ & 1.00 \\
\hline Connective tissue & 4 & 14 & $1.1(0.4-3.5)$ & 0.77 \\
\hline Breast & 86 & 338 & $1.0(0.8-1.3)$ & 0.85 \\
\hline Cervix & 35 & 115 & $1.2(0.8-1.8)$ & 0.17 \\
\hline Uterus & 13 & 80 & $0.7(0.4-1.3)$ & 0.87 \\
\hline Ovary & 15 & 70 & $0.9(0.5-1.5)$ & 0.10 \\
\hline Vulva & 2 & 10 & $0.8(0.17-3.7)$ & 0.72 \\
\hline Prostate & 55 & 239 & $0.9(0.7-1.2)$ & 0.56 \\
\hline Testicular & 11 & 28 & $1.6(0.8-1.8)$ & 0.17 \\
\hline
\end{tabular}

${ }^{1}$ All estimates were adjusted for sex of first-degree relative.

Details of the study population have been described previously [9]. In brief, Sweden provides universal medical health care for the entire population, which is currently approximately 9 million people. Since 1958, all physicians, pathologists and cytologists in Sweden have been obliged by law to report each case of cancer they diagnose or treat to the centralized nationwide Swedish Cancer Registry.

In a validation study that focused on lymphoproliferative malignancies diagnosed from 1 January 1964 through 31 December 2003, we found the overall completeness and diagnostic accuracy of the registry to be $>90 \%$. For WM, the diagnostic accuracy was $93 \%$, but the completeness was $68 \%$ [21]. To compensate for the low completeness, we used parallel approaches to establish a nationwide LPL/WM cohort. First, we identified all LPL/WM patients who were diagnosed from 1 January 1958 through 31 December 2005 in the nationwide Swedish Cancer Registry. Second, we retrieved information on patients with incident LPL/WM through our national network including all major hematology or oncology units in Sweden. Third, we identified all patients reported in the Swedish Inpatient Registry, which captures information on individual patient-based discharge diagnosis and discharge listings from all inpatient care, with a very high coverage. For each LPL/ WM patient, 4 population-based controls (matched by sex, year of birth and county of residence) were chosen randomly from the Swedish population database. All controls had to be alive at the time of LPL/WM diagnosis for the corresponding case and with no previous hematological malignancy at the date of the corresponding case's diagnosis. Using the Swedish Multigenerational Registry [22], we obtained information on all first-degree relatives (parents, siblings and offspring) of LPL/WM patients and controls. All LPL/ WM patients and controls without linkable relatives were removed from the study. As a final step, we conducted record linkages with the Swedish Cancer Registry and a nationwide myeloproliferative disorders cohort, described elsewhere [23], to obtain information on myeloid hematological malignancies and solid tumors among first-degree relatives of LPL/WM patients and controls. The statistical methods have been described in detail previously $[24,25]$. 
case WM and 46 mixed WM/related B-cell disorder kindred as well as 28 sporadic WM patients, familial WM patients were more likely than unaffected relatives to report a history of autoimmune disease and infections [15]. Familial WM patients were also more likely to report exposure to farming, pesticides, wood dust and organic solvents compared with unaffected family members. In a recent study based on 2,470 LPL/WM patients, 9,698 matched controls and almost 30,000 first-degree relatives of cases and controls from Sweden, we analyzed whether personal or family history of a wide range of autoimmune, infectious, allergic, and inflammatory conditions were associated with LPL/WM [14]. A personal history of several autoimmune and other immune-related disorders was associated with an increased risk of LPL/WM. Interestingly, a family history of Sjögren's syndrome, autoimmune hemolytic anemia, GuillainBarré syndrome, cytomegalovirus, gingivitis and periodontitis, and chronic prostatitis was associated with an increased risk of LPL/WM [14]. Our findings that both personal and family history of Sjögren's syndrome or autoimmune hemolytic anemia were associated with an increased risk of LPL/WM indicate that there might be some shared (genetic, environmental, or both) susceptibility for these conditions. Future work is needed to uncover the underlying mechanisms of the observed associations. These studies provide novel information supporting the application of gene mapping and candidate gene approaches in high-risk families and case-control studies.

\section{Genetic Studies and LPL/WM}

There are a number of gene candidates that could contribute to a susceptibility to LPL/WM and related conditions. For example, polymorphisms in lymphomagenesis, immune function and DNA repair genes have been found to be associated with an elevated risk of chronic lymphocytic leukemia [16], Hodgkin lymphoma [17] and nonHodgkin lymphoma [18]. In a genome-wide linkage analysis of 11 high-risk WM families (a total of 122 individuals, including $34 \mathrm{WM}$ patients and 10 IgM MGUS patients), the strongest evidence of linkage was found on chromosomes 1q and 4q [7]. Other locations suggestive of linkage were found on chromosomes 3 and 6 . Future work is needed to identify gene(s) that modulate susceptibility to LPL/WM.

\section{Genetic Anticipation}

Genetic anticipation refers to an earlier age at onset or increasing severity of a disease in successive generations. Trinucleotide repeat expansions explain anticipation in some diseases, and epigenetic changes and abnormalities in telomeres have also been suggested as possible mechanisms that may contribute to anticipation $[19,20]$. In their study, Treon et al. [8] showed that WM patients with a family history of WM or a plasma cell disorder were diagnosed at a younger age than sporadic WM cases. In our large population-based study, we found that offspring of LPL/WM patients were diagnosed with LPL/WM at an earlier age than the parent group. However, the age at diagnosis of LPL/WM was similar in offspring of controls and of cases, indicating that this difference is likely due to differences in follow-up time between generations and not explained by earlier diagnosis in children of parents with LPL/WM. This needs to be studied in more detail.

\section{Summary and Conclusions}

In summary, first-degree relatives to LPL/WM patients have an increased risk of several lymphoproliferative disorders, but not other malignancies. In addition, there is familial aggregation of some immune-related conditions. These results support the hypothesis that there are shared susceptibility genes that predispose to LPL/WM and other lymphoproliferative disorders. Future studies are needed to identify susceptibility genes and define the role of immune-related conditions, and their interaction, in the etiology of LPL/WM.

\section{Acknowledgements}

This research was supported by grants from the Swedish Cancer Society, Stockholm County Council, the Karolinska Institutet Foundations, and the Intramural Research Program of the $\mathrm{Na}$ tional Institutes of Health, National Cancer Institute, as well as by an unrestricted grant from Roche. The authors thank Ms. Shiva Ayobi, The National Board of Health and Welfare, Stockholm, Sweden, Ms. Susanne Dahllöf, Statistics Sweden, Orebro, Sweden, and Ms. Emily Steplowski, Information Management Services, Silver Spring, Md., USA, for their important efforts. 


\section{References}

1 Owen RG, Treon SP, Al-Katib A, Fonseca R, Greipp PR, McMaster ML, Morra E, Pangalis GA, San Miguel JF, Branagan AR, Dimopoulos MA: Clinicopathological definition of Waldenström's macroglobulinemia: consensus panel recommendations from the second international workshop on Waldenström's macroglobulinemia. Semin Oncol 2003;30: 110-115.

2 Björkholm M: Lymphoplasmacytic lymphoma/Waldenström's macroglobulinemia; in Canellos G, Lister A, Young B (eds): The Lymphomas, ed 2. Philadelphia, Saunders, 2006, pp 374-380.

$>3$ Groves FD, Travis LB, Devesa SS, Ries LA, Fraumeni JF Jr: Waldenström's macroglobulinemia: incidence patterns in the United States, 1988-1994. Cancer 1998;82:10781081.

4 Kyle RA, Therneau TM, Rajkumar SV, Remstein ED, Offord JR, Larson DR, Plevak MF, Melton LJ 3rd: Long-term follow-up of IgM monoclonal gammopathy of undetermined significance. Blood 2003;102:3759-3764.

$\checkmark 5$ Kristinsson SY, Koshiol J, Goldin LR, Bjorkholm M, Turesson I, Gridley G, McMaster $\mathrm{ML}$, Landgren O: Genetics- and immunerelated factors in the pathogenesis of lymphoplasmacytic lymphoma/Waldenström's macroglobulinemia. Clin Lymphoma $\mathrm{My}-$ eloma 2009;9:23-26.

6 Linet MS, Humphrey RL, Mehl ES, Brown LM, Pottern LM, Bias WB, McCaffrey L: A case-control and family study of Waldenström's macroglobulinemia. Leukemia 1993; 7:1363-1369.

7 McMaster ML, Goldin LR, Bai Y, Ter-Minassian $M$, Boehringer S, Giambarresi TR, Vasquez LG, Tucker MA: Genomewide linkage screen for Waldenström macroglobulinemia susceptibility loci in high-risk families. Am J Hum Genet 2006;79:695-701.

$>8$ Treon SP, Hunter ZR, Aggarwal A, Ewen EP, Masota S, Lee C, Santos DD, Hatjiharissi E, $\mathrm{Xu}$ L, Leleu X, Tournilhac O, Patterson CJ, Manning R, Branagan AR, Morton CC: Characterization of familial Waldenström's macroglobulinemia. Ann Oncol 2006;17: 488-494.
9 Kristinsson SY, Bjorkholm M, Goldin LR, McMaster ML, Turesson I, Landgren O: Risk of lymphoproliferative disorders among first-degree relatives of lymphoplasmacytic lymphoma/Waldenström macroglobulinemia patients: a population-based study in Sweden. Blood 2008;112:3052-3056.

10 Goldin LR, Landgren O, McMaster ML, Gridley G, Hemminki K, Li X, Mellemkjaer L, Olsen JH, Linet MS: Familial aggregation and heterogeneity of non-Hodgkin lymphoma in population-based samples. Cancer Epidemiol Biomarkers Prev 2005; 14:24022406.

11 Goldin LR, Pfeiffer RM, Li X, Hemminki K: Familial risk of lymphoproliferative tumors in families of patients with chronic lymphocytic leukemia: results from the Swedish Family-Cancer Database. Blood 2004;104: 1850-1854.

12 Goldin LR, Pfeiffer RM, Gridley G, Gail MH, Li X, Mellemkjaer L, Olsen JH, Hemminki K, Linet MS: Familial aggregation of Hodgkin lymphoma and related tumors. Cancer 2004; 100:1902-1908.

13 Altieri A, Bermejo JL, Hemminki K: Familial aggregation of lymphoplasmacytic lymphoma with non-Hodgkin lymphoma and other neoplasms. Leukemia 2005;19:23422343.

14 Kristinsson SY, Koshiol J, Bjorkholm M, Goldin LR, McMaster ML, Turesson I, Landgren $\mathrm{O}$ : Immune-related and inflammatory conditions and risk of lymphoplasmacytic lymphoma or Waldenström macroglobulinemia. J Natl Cancer Inst 2010;102:557-567.

15 Royer RH, Koshiol J, Giambarresi TR, Vasquez LG, Pfeiffer RM, McMaster ML: Differential characteristics of Waldenström macroglobulinemia according to patterns of familial aggregation. Blood 2010;115:44644471 .
16 Rudd MF, Sellick GS, Webb EL, Catovsky D, Houlston RS: Variants in the ATM-BRCA2CHEK2 axis predispose to chronic lymphocytic leukemia. Blood 2006;108:638-644.

17 Hohaus S, Massini G, D’Alo F, Guidi F, Putzulu R, Scardocci A, Rabi A, Di Febo AL, Voso MT, Leone G: Association between glutathione S-transferase genotypes and Hodgkin's lymphoma risk and prognosis. Clin Cancer Res 2003;9:3435-3440.

18 Skibola CF, Curry JD, Nieters A: Genetic susceptibility to lymphoma. Haematologica 2007;92:960-969.

19 Lindblad K, Schalling M: Expanded repeat sequences and disease. Semin Neurol 1999; 19:289-299.

20 Vulliamy T, Marrone A, Szydlo R, Walne A, Mason PJ, Dokal I: Disease anticipation is associated with progressive telomere shortening in families with dyskeratosis congenita due to mutations in TERC. Nat Genet 2004; 36:447-449.

21 Turesson I, Linet MS, Bjorkholm M, Kristinsson SY, Goldin LR, Caporaso NE, Landgren O: Ascertainment and diagnostic accuracy for hematopoietic lymphoproliferative malignancies in Sweden 1964-2003. Int J Cancer 2007;121:2260-2266.

22 Skarle A: Flergenerationsregistret. Stockholm, Statistics Sweden, Population Statistics, 2001

-23 Landgren O, Goldin LR, Kristinsson SY, Helgadottir EA, Samuelsson J, Bjorkholm M: Increased risks of polycythemia vera, essential thrombocythemia, and myelofibrosis among 24,577 first-degree relatives of 11,039 patients with myeloproliferative neoplasms in Sweden. Blood 2008;112:2199-2204.

24 Pfeiffer RM, Goldin LR, Chatterjee N, Daugherty S, Hemminki K, Pee D, X LI, Gail MH: Methods for testing familial aggregation of diseases in population-based samples: application to Hodgkin lymphoma in Swedish registry data. Ann Hum Genet 2004;68:498-508.

-25 Liang KY: Estimating effects of probands' characteristics on familial risk. 1. Adjustment for censoring and correlated ages at onset. Genet Epidemiol 1991;8:329-338. 